\title{
Teaching Strategies for Chinese Students to Study in English-speaking Countries
}

\author{
Lin Chen \\ Chengdu Aeronautic Polytechnic, China
}

\begin{abstract}
Existing studies mainly focuses on the learning shocks among Chinese students who obtain crossnational education in English-speaking countries, which involves in language incompetency, academic culture shock and psychological frustration. Within these difficulties, this study particular investigates academic culture shock relating teaching pedagogies which is not fully investigated in existing studies. The results suggest that Chinese students experienced different levels of difficulties towards teaching strategies. Therefore, better preparation before Chinese students studying abroad perhaps need to emphasize more on those teaching pedagogies they are unacquainted with and do not competent to participate in.
\end{abstract}

\section{Introduction}

Misconceptions In terms of the pedagogical practices of English-speaking classrooms, this study employed Roy Killen's [11] and [12] theoretical framework which summarised the different teaching strategies, based on the characteristics of the teaching and learning activities. Killen [12] noted that the techniques that have been used to facilitate learning are regardless of a specific discipline. According to Killen [12], there are seven different teaching strategies that are commonly used in Australian classrooms: direct instruction, (whole) classroom discussion, small-group work, cooperative learning, problem solving, student research, and performance activities. The Table 1 provides a description of each teaching strategy.

Based on Killen's work, this research divides these seven teaching strategies into three groups: presentation-based teaching strategies, interactionbased teaching strategies and inquiry-based teaching strategies. The rationale for this division involves a consideration of the major skills that are required for student participation in these teaching strategies. However, the traditional way of grouping these strategies is teacher-centred or student-centred [12]. Killen [12] suggested that direct instruction is the most teacher-centred, while student performance activities (e.g., writing) are the most student-centred. Yet this division received criticism from Chen and Sit [6], who argued that the central role of teacher and student may shift during the process of teaching and learning. Alexander [1] believed that the division of pedagogical practices into teacher-centred and student-centred is a simplified binary, and went on to argue that mainstream pedagogical research needs to abandon this dichotomy. Taking into consideration these criticisms, this study re-categorised these teaching strategies into three groups: interactionbased, inquiry-based and presentation-based. The interaction-based teaching strategies include smallgroup work, classroom discussions and cooperative learning. The inquiry-based teaching strategies are problem solving and student research. The third group is presentation-based teaching strategies and includes direct instruction and performance activities. The aim of grouping the teaching strategies in this way was to allow the researcher to identify the central characteristics of the classroom teaching. It could further assist the researcher to explore the common pedagogical challenges that the Chinese cohort confronted in Anglophone classrooms.

Table 1. Descriptions of Teaching Strategies [12]

\begin{tabular}{|c|c|}
\hline Teachingstrategies & Descriptions \\
\hline Direct instruction & $\begin{array}{l}\text { A teacher delivers academic content in a } \\
\text { highlystructured format, basic form of delivery } \\
\text { is lecture. }\end{array}$ \\
\hline (Whole) class discussion & $\begin{array}{l}\text { A cohort of students has small class tutorials } \\
\text { and whole-class discussions. }\end{array}$ \\
\hline Small-group work & $\begin{array}{l}\text { At least two or more students work together } \\
\text { under a formally structured learning } \\
\text { environment. }\end{array}$ \\
\hline Cooperative learning & $\begin{array}{l}\text { The students work on a task in groups of two } \\
\text { or more and are encouraged to help one } \\
\text { another to learn. }\end{array}$ \\
\hline Problemsolving & $\begin{array}{l}\text { The students focus on a task that requires } \\
\text { them to solve some realistic problem through } \\
\text { multiple solutions individually or in small } \\
\text { groups. }\end{array}$ \\
\hline Student research & $\begin{array}{l}\text { A task which engages students in using } \\
\text { suitable ways of gathering data, interpret the } \\
\text { information they find, and reach conclusions } \\
\text { based on the analysis of the information. }\end{array}$ \\
\hline Performance activities & $\begin{array}{l}\text { One or more students play a role in some } \\
\text { activities such as a scripted play, debating. } \\
\text { role play, classroom presentation. }\end{array}$ \\
\hline
\end{tabular}

\section{Methodologies}

This study employs a mixed methods research approach to examine the international Chinese students' pedagogical challenges and the pedagogical 
preparations that they received before studying in English-speaking countries. This area is a complicated educational issue, as it involves three relevant cohorts, including international Chinese students in Australian universities; English teachers and Chinese students in Australian language centres; and College English teachers and students in China. These investigations are associated with the teaching practices and learning experiences, therefore both quantitative and qualitative studies have been used for the examination of this complicated issue to compensate for the disadvantages of using a single method.

With regard to the combination and integration of both quantitative and qualitative methods, Creswell [7] suggests two types of research design: a convergent parallel design and an explanatory sequential design by presenting diagrams. This study used the convergent parallel design (Figure 1) with a modification to better answer the research questions (Figure 2). One intension of using a convergent parallel design is that, as Creswell and Clark [8] argued, comparing qualitative and quantitative data can show if they converge and provide similar results. This study conducted the qualitative interviews to identify the pedagogical challenges and preparation of Chinese students before undertaking their cross-national education. Concurrently, quantitative surveys were used to examine the practices of how these students are prepared, in terms of pedagogical strategies, in Chinese universities and Australian language centres. This study then merges the results from both the quantitative interviews and the qualitative surveys. One of the aims is to interpret if the students' responses to their preparation regarding pedagogical strategies are convergent or divergent to the teachers' reports. Another intension for using a convergent parallel design is to offset the weakness of one instrument for data collection. This rationale is similar to using a mixed methods approach, but with the emphasis on the difference to the explanatory sequential design, which usually contains two consecutive phases of study. Collecting quantitative or qualitative data commences first, and is then followed by gathering the qualitative or quantitative data to help explain or elaborate on the data in the first phase. Creswell [7] argues that the models of explanatory sequential design often regard the data gathered in the first phase as a base to develop the variables or instruments for the second phase investigation. Yet this study gives equal priority to both the quantitative and qualitative data by using the convergent parallel design to examine whether the current pedagogical preparations for Chinese students are sufficient or not, in the perspectives of both the teachers and students. Based on the results, this study determines if the current preparations are sufficient for preparing students' cross-national education. In order to acquire the comprehensive data, this study also simultaneously collected the quantitative data and qualitative data by using the research instrument of classroom observations (Figure 2). The purpose of this modification of Creswell's [7] model is to gather more detailed data to complement the data acquired from the teacher surveys regarding their teaching practices and the interviews regarding students' responses. This study involves three groups: (1) Chinese postgraduate students who are studying in English-speaking classrooms; (2) the English language preparation instructors and the Chinese students who are in the process of preparation in Australian universities; and (3) College English instructors and students at Chinese universities.

The multiple types of participants allow the researcher to develop a critical understanding from different perspectives [3]. For example, one cohort of Chinese students who are undertaking postgraduate study in Australian universities was interviewed to understand their initial pedagogical difficulties. Two other cohorts in Chinese universities and Australian language centres were investigated to understand how Chinese students are prepared before undertaking their cross-national education. The results from these investigations provided the researcher with a thorough comprehension of these issues.

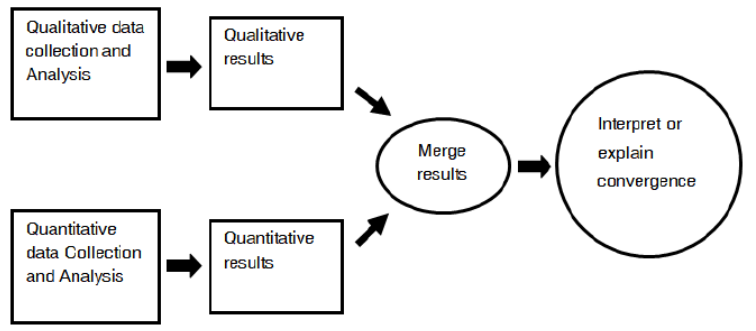

Figure 1. Convergent parallel Design [7]

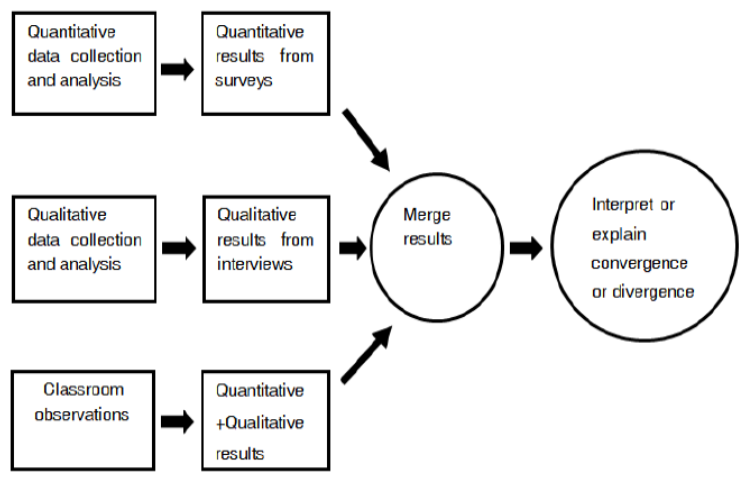

Figure 2. Modified Convergent parallel Design

\section{Results}

International Chinese students were sampled to articulate their learning experiences in Australian 
classrooms. These experiences were found to include a range of learning shocks. This conformed to the results of prior studies that concluded Chinese students are still confronted with learning shocks, meaning (some) Chinese students experience discomfort and frustration in English-speaking classrooms. This result highlights that it is necessary and significant to provide preparations for Chinese students before they undertake cross-national education. With regards to the factors that cause learning shocks, this study suggests that the learning shock was partly caused by an absence of language proficiency.

A small number of students illustrated their difficulties, due to language incompetency, and particularly where their oral English proficiency was relatively low, which hindered them in speaking publicly in Australian classrooms. Nevertheless, the learning shock was also strongly influenced by the teaching strategies being used. The pedagogies being used were most likely to contribute to the learning shocks. During interviews, almost all the student participants reported that they were extremely challenged by inquiry-based teaching strategies, including problem solving and student research. In addition, the majority of students indicated that they were unfamiliar with peer interaction and had only limited interactions with teachers.

It is worth noting that not all of the teaching strategies challenged Chinese students and caused a learning shock. For example, no student participant reportedly had difficulty and barriers to participating in the teaching strategy of direct instruction. This finding has not been discussed in the current literature, which only briefly discussed learning shock where "students are unfamiliar with teaching conventions and approaches" [10]. This study identified particular teaching strategies that challenged Chinese students and which particular teaching strategies were relatively easy for Chinese students to participate in. The data further indicated that the Chinese students experienced different degrees of learning shock. In the other words, they experienced a hierarchy of discomfort and anxiety.

The learning shocks were mainly caused by the inquiry-based teaching strategies and interactionbased teaching strategies. In particular, the Chinese students experienced the highest levels of learning shock in relation to inquiry-based teaching strategies. Much of the literature suggests that learning shock is a response that occurs when the students' perceived learning values, beliefs and conventions that are different from those in English-speaking countries (including Australia, Canada, New Zealand, the UK and the USA). For example, Brick [2], who examined Anglophone countries, argued that they may be unfamiliar to students from China. This perspective stresses the differences in academic cultures between Chinese and English-speaking universities. Therefore, the academic cultures affect the students' values and beliefs regarding the teaching and learning. In addition, the results of this study also strongly suggest that student' competency in pedagogical skills plays an important role.

The interview data indicated that there is an inconsistency between the Chinese students' positive attitudes and their performances in teaching strategies. For example, the Chinese students were extremely challenged by inquiry-based teaching strategies, but they expressed a strong desire to conduct an inquiry assignment appropriately, which requires being critical. This result was not in line with the stereotyping of Chinese students as apathetic, obedient learners based on their Confucian cultural background. Instead, in this study the Chinese students' passive behaviours in explorative tasks were identified as originating from a lack of inquiry skills.

Similarly, the interview data also shows the students' appreciation of the interaction-based teaching strategies, despite a lack of interpersonal skills. To label Chinese students as reticent and reluctant to cooperate in an academic environment is arguably a misleading of what is occurring. The interview data demonstrated that the pedagogical gaps strongly affect the Chinese students in regard to their learning styles and performances in teaching strategies, except that cultural beliefs they are embedded with. This finding covers new ground by identifying that the learning shocks are largely associated with specific pedagogical strategies. The pedagogical preparations therefore are necessary and important for Chinese students before their crossnational education. These preparations, which need to pay more attention to pedagogical skills, are intended to assist them to cope with the learning shock in English-speaking universities, in order that they will be able to achieve better academic outcomes.

While many scholars have emphasised the learning shocks to understand the learning experiences of Chinese students in English-speaking universities, Chinese students still reported positive experience in some teaching techniques, such as supportive academic workshops in English-speaking universities. The perceived benefits they gained from particular teaching techniques often contributed to their study in English-speaking classrooms.

The pedagogical preparations need to respond to the challenges and also makes use of the techniques which could benefit Chinese students. From the empirical data, it can be concluded that the overall experience of Chinese students cannot only be simply described as learning shocks. These shocks are not only related to students' perceived learning styles that different from English-speaking universities, but also showed as a close association with a range of pedagogical skills. 


\subsection{Current preparations in Australian language centres}

The English language centres in Australian universities divide English language classes into EGP and EAP. This classification reflects the diverse teaching purposes in the classes of Australian language centres. EGP classes focus more on forms (including syntax, lexis and semantics), while EAP is more about language use in academic contexts and the skills for tertiary study. In other words, English language teaching in Australian language centres does not merely consolidate the foundations of English language and skills, but both teachers and students have a specific purpose of preparing for university study in Australia. However, as mentioned earlier, the international Chinese students in this study experienced various challenges with the teaching strategies, including unsatisfying interactions with teachers and peers, and insufficient inquiry skills. These results imply that if the teaching focus of EAP courses is primarily on language and skills, this teaching practice is inadequate to cater for a group of Chinese students who transfer from the Chinese instructional system to the Australian system.

With regard to the teaching strategies, according to the survey data, the teachers in Australian language centres employed interaction-based teaching strategies most frequently, followed by presentation-based teaching strategies and then inquiry-based teaching strategies.

The classroom observations also showed that Australian language centres provided students with more opportunities for exposure to the different teaching strategies, compared with College English classrooms in China.

The results argue that, international Chinese students will experience diverse teaching strategies in Australian mainstream classrooms, so it is important that they experience such strategies as a part of their preparation for successful study in Australian universities.

In addition, the classroom observations in Australian language centres also found that Chinese students need to be prepared to participate in interaction-based teaching strategies in a multicultural environment, because the Chinese cohort was the major source of international students in the language centres. As such, the implementation of an interaction-based teaching strategy is affected by the classroom environment. It can be concluded that even though teachers frequently use this teaching strategy, there are still limited opportunities for Chinese students to practice interactions with peers who are from other linguistic cultural backgrounds, which was reported by Chinese postgraduate students.

\subsection{Current preparations in Chinese classrooms for cross-national education}

Based on the analysis of the students' responses, it indicated that teaching focuses, namely the question of what English language classes teach, did not respond promptly to the diverse learning purposes of the students. The empirical data of interviews confirmed that these non-English majors have different purposes in learning English. Some students study College English for further education in English-speaking universities, and others students are for postgraduate degrees in Chinese universities, whereas some students study for their career development. However, College English in its design and practice does not take account of these differences in purpose and remains focused on EGP. This finding is consistent with existing studies, such as Cai [4], [5] and $\mathrm{Du}$ [9] who argue that the curriculum design of College English, the teaching content and its aims, are in general for developing students' English levels with regard to daily English, without a specification of particular purposes.

The interview data further identified what kind of specific purposes that College English students poses and how these purposes could affect the course design of College English programs. For example, an identified purpose of learning College English is for cross-national education, which is the focus of this study. This empirical data suggests that College English focuses on English language proficiency. With this in mind, it does not correspond well to students' reported pedagogical challenges and that it needs to better provide insufficient preparations for College English students, who have intension for cross-national education.

Another dimension of preparation that this research addresses is instructional strategies, in other words, how to teach in order to prepare Chinese students for cross-national education. The quantitative data of the mean scores indicated that College English teachers did not use a wide range of teaching strategies. This teaching practice does not satisfy students, in terms of their pedagogical preferences and also does not respond to the pedagogical challenges that the Chinese cohort confront in English-speaking classrooms. Direct instruction was the dominant teaching strategy in College English classrooms, and was the most preferred teaching strategy among the College English teachers. This finding implies that Chinese students are well accustomed to this presentationbased teaching strategy and it is not surprising that nearly all international Chinese students did not report experiencing difficulties with this teaching strategy of direct instruction. Despite the unchallenging learning experience of direct instruction, they reported that this form of didactic teaching led to their passive roles in classes and 
limited interactions with teachers and peers. It again reinforced that Chinese students exhibited a desire to be exposed to interactive learning environments. However, the teachers' reports and classroom observations suggested that College English teachers did not use interaction-based teaching strategies often, and only rarely used inquiry-based teaching strategies.

The disjuncture between the teaching strategies and the students' preferences for teaching strategies implies that the current College English programs do not satisfy the College English students. Aside from their preferences, the interview data suggested that the international Chinese students experienced challenges in interaction-based and inquiry-based teaching strategies. One primary reason for these challenges is that of a lack of skills, including interaction and inquiry skills. These challenges could be better managed if College English teachers responded to the students' inabilities regarding pedagogical skills in the processes of their preparations.

In general, the current preparation through College English is not adequate for the Chinese students' cross-national education. The teaching mainly targets improving Chinese students' English language proficiency, while pedagogical preparation is not well-established. Teachers in College English classrooms rarely used inquiry-based teaching strategies, and had limited and ineffective use of interaction-based teaching strategies. These teaching practices are not adequate to prepare Chinese students who are participating in Australian classrooms, where multiple teaching strategies are being used.

The preparations in Australian language centres made improvements by considering the students' academic needs and by dividing the classes into EAP and EGP. However, in its EAP classes, the preparations are limited to language and academic skills. Inquiry-based teaching strategies were also found to be rarely used, and students therefore lack preparation in such teaching strategies. The pedagogical preparations in the English language centres are not abundant, apart from their teaching focus and instructional strategies.

The Table 2 summarises the status and evaluations of the current preparation programs. As can be seen, the current preparations in both China and Australia are not adequate and need further improvements, in particular the teaching strategies, to better prepare Chinese students. This is because language proficiency and pedagogical competency are equally important for the Chinese students' crossnational education, contributing to their positive and pleasant learning experiences in Anglophone universities.
Table 2. Current preparation programs in China and Australia

\begin{tabular}{|c|c|c|c|c|}
\hline Teaching & \multicolumn{2}{|c|}{$\begin{array}{l}\text { College English } \\
\text { (China) }\end{array}$} & \multicolumn{2}{|c|}{$\begin{array}{l}\text { Language centres } \\
\text { (Australia) }\end{array}$} \\
\hline \multirow{2}{*}{$\begin{array}{l}\text { Teaching } \\
\text { focus }\end{array}$} & $\begin{array}{l}\text { Language and } \\
\text { skills }\end{array}$ & EGP & Language and skills & EGP and EAP \\
\hline & Pedagogy & No & Pedagogy & No \\
\hline \multirow{3}{*}{$\begin{array}{l}\text { Instructional } \\
\text { strategies }\end{array}$} & Presentation-based & Yes & Presentation-based & Yes \\
\hline & Interaction-based & Limited use & Interaction-based & $\begin{array}{l}\text { Frequently } \\
\text { used, but } \\
\text { needs to be } \\
\text { improved }\end{array}$ \\
\hline & Inquiry-based & $\begin{array}{l}\text { Little } \\
\text { preparation }\end{array}$ & Inquiry-based & $\begin{array}{l}\text { Little } \\
\text { preparation }\end{array}$ \\
\hline
\end{tabular}

\section{Multi-participatory Model for Pedagogical Competency}

The empirical data showed that the preparations in Australia have flaws in relation to the pedagogical preparation of Chinese students. As such, Chinese students cannot afford to wait until they study in Australian language centres to be prepared. This section highlights the identified problems in Australian language centres and targets the reform of College English programs to better prepare Chinese students, especially in pedagogical strategies. To provide sufficient pedagogical preparation for the Chinese students before their cross-national education commences, it is crucial to consider the reform of the most relevant curriculum, namely College English, for this cohort. From this perspective, a multi-participatory model includes three dimensions: the curricula of the College English programs, and the teachers and students who are conducting the pedagogical preparation.

\section{Recommendations}

Firstly, dimension One is regarding the design of curricula. In details, there are two proposed recommendations: (1) the current College English programs could become more inclusive in three stages: from the current general English to English for special purposes, and then to English for academic purposes. In the EAP courses, more attention should be given to the pedagogy, which is particularly relevant to students' aspirations to undertake cross-national education; (2) College English curricula need to consider providing ongoing training after the two years' teaching duration. In 
particular, the curricula need to identify groups of students who are studying for the purposes of crossnational education.

Secondly, dimension two is from the perspectives of teachers' strategies and the classroom environment. In details, there are five proposed recommendations: (1) The pedagogical preparations for future Chinese students should be a part of the EAP teaching within the third and fourth year' classes, and can involve diverse teaching strategies delivered in a progressive way; (2) With regard to the preparation of inquiry-based teaching strategies, the following three steps need to be included in the preparation process: teacher presentations; student practices, and teachers and students' assessments of the preparation ; (3) College English teachers need to build collaborative learning communities in classrooms to build the students' readiness for interaction-based teaching strategies; (4) In terms of the preparation of presentation-based teaching strategies, College English teachers need to create an inclusive classroom environment. Namely, College English students should be provided with the opportunities for active and meaningful participation in classroom activities; (5) College English teachers need to have substantial, ongoing, professional development in pedagogical skills by being reflective and critical teaching practioners, as well as universities working to facilitate students' pedagogical preparation.

Thirdly, Dimension three extends to the participation of College English students. In details, there is one proposed recommendation: College English students need to consciously prepare for strategies to overcome the pedagogical challenges they may confront within English-speaking universities. These preparations will include selfconstructing a solid knowledge base and vigorously developing different types of pedagogical skills. The three dimensions are interrelated and each contributes to the pedagogical preparation of Chinese students. Two recommendations are related to the curriculum design of College English curricula, while five recommendations are related to the College English teachers and the classroom environment, while one recommendation is pertinent to the Chinese students themselves. The aim of pedagogical preparation is to help students to establish their pedagogical competency, which includes two aspects of the abilities that students are expected to have established with their pedagogical preparation. These abilities are a solid knowledge base and vigorous pedagogical skills.

\section{Conclusion}

With regard to the knowledge and practices of pedagogies, scholars often analyse these from the perspective of teacher preparation (e.g., Liakopoulou
[13], Killen [13] and [12]). However, this study highlights the significance of the students' pedagogical preparation. A better preparation can potentially contribute to the learning outcomes of students and their academic performances in English-speaking classrooms. Additionally, it can potentially also facilitate the intangible values for students when they study in English-speaking classrooms, including positive emotions in the classrooms, self-confidence and a dedicated intention to engage in teaching strategies.

\section{References}

[1] Alexander, R. J. (2001). Border crossings: Towards a comparative pedagogy. Comparative Education, 37(4), 507-523.

[2] Brick, J. (2011). Academic culture: A student's guide to studying at university (2nd ed.). South Yarra, Vic.: Macmillan.

[3] Calder, A. (2004). Peer interaction in the transition process. Journal of the Australia and New Zealand Student Services Association, 23(1), 4-16.

[4] Cai, J. G. (2005). Thinking on the issues of College English teaching. Foreign Language Teaching and Research, 37(2), 83-91.

[5] Cai, J. G. (2012). Reanalysis of the goal of College English teaching in the perspective of globalisation. Foreign Languages and Their Teaching, 3(1), 5-8.

[6] Chen, S., and Sit, H. W. (2009). A comparative study of the responses by international students towards the teaching strategies used in an Australian university. The International Journal of Learning, 16(9), 495-504.

[7] Creswell, J. W. (2008). Educational research: Planning, conducting, and evaluating quantitative and qualitative research (3rd ed.). Upper Saddle River, N.J.: Pearson/Merrill Prentice Hall.

[8] Creswell, J. W., and Clark, V. (Eds.). (2011). Designing and conducting mixed methods research. Thousand Oaks, CA: Sage.

[9] Du, H. (2012). College English teaching in China: Responses to the new teaching goal. TESOL in Context, 3(1), 1-13.

[10] Griffiths, D. S., Winstanley, D., and Gabriel, Y. (2005). Learning shock: The trauma of return to formal learning. Management Learning, 1(36), 275297. 
[11] Killen, R. (2007). Effective teaching strategies: Lessons from research and practice (4th ed.). South Melbourne, Vic.: Thomson Social Science Press.

[12] Killen, R. (2013). Effective teaching strategies: Lessons from research and practice (6th ed.). Sydney, NSW.: Cengage Learning Australia.

[13] Liakopoulou, M. (2011). Teachers' pedagogical competence as a prerequisite for entering the profession. European Journal of Education, 46(4), $474-488$. 